\title{
Analyzing the Coupling Coordination among Economic, Social, and Environmental Benefits of Urban Infrastructure: Case Study of Four Chinese Autonomous Municipalities
}

\author{
Yu Sun $\mathbb{D}^{1,2}$ and Yin Cui $\mathbb{D}^{1}$ \\ ${ }^{1}$ College of Management and Economics, Tianjin University, Tianjin 300072, China \\ ${ }^{2}$ School of Public Administration, Tianjin University of Commerce, Tianjin 300134, China \\ Correspondence should be addressed to Yin Cui; cuiyin86@126.com
}

Received 26 September 2017; Revised 6 December 2017; Accepted 21 June 2018; Published 8 July 2018

Academic Editor: Anna M. Gil-Lafuente

Copyright (c) 2018 Yu Sun and Yin Cui. This is an open access article distributed under the Creative Commons Attribution License, which permits unrestricted use, distribution, and reproduction in any medium, provided the original work is properly cited.

\begin{abstract}
Urban infrastructure is a necessary condition for urban development. Its use generates three benefits which are economic, social, and environmental benefits of urban infrastructure. They are the positive impacts on urban economy, society, and environment generated by the use of urban infrastructure, respectively. This paper evaluates the coupling coordination among these three benefits taking four Chinese autonomous municipalities as examples. These four cities have large-scale urban infrastructure but its basic function has not been fully fulfilled. Whether three benefits of urban infrastructure have been developed in harmony or not was unclear. We analyzed the coordinated development among three benefits by constructing coupling coordination degree model and studied the impacts of three benefits on their coupling coordination degree using panel regression model. The results showed that the levels of coordinated development among three benefits of urban infrastructure were low in these four cities and the impact of social benefit on their coordinated development was largest. Therefore, urban infrastructure social benefit needs to be improved mainly in these four cities.
\end{abstract}

\section{Introduction}

With the acceleration of urbanization in recent years, many Chinese cities have initially established an integrated urban infrastructure system. This system provides the basic substance guarantee for the development of urban economy [13]. At the same time, the construction of urban infrastructure changes urban living condition which is beneficial to promote the development and progress of society $[4,5]$. In addition, urban infrastructure has positive influence on the protection of urban ecological environment [6-8]. Therefore, the use of urban infrastructure has important impact on urban economic, social, and environmental systems.

The economic, social, and environmental benefits of urban infrastructure are the positive impacts on urban economy, society, and environment generated by the use of it respectively. Many scholars have used plenty of methods to study these impacts. Urban infrastructure economic benefit is the positive influence of infrastructure on urban economic development via external effect and spillover effect $[9,10]$. The construction of urban infrastructure promotes the development of other industries and increases urban GDP [1113] which is helpful to raise the levels of fiscal revenue of urban government $[13,14]$ and consumption expenditure of urban inhabitants $[15,16]$. The well-conditioned urban infrastructure attracts the investment by reducing production and transportation cost $[17,18]$. The establishment of urban infrastructure is also conducive to urban export $[19,20]$.

Urban infrastructure social benefit is the positive function of urban infrastructure in the process of promoting urban social progress. Urban social progress refers to not only the rapid development of urban economy but also the comprehensive development of urban residents. The construction of urban infrastructure is beneficial for recruiting new workers and raising employment rate [21-24]. The increase of labor demand raises the wage level of employed persons which is helpful to add the disposable income of urban population. In addition, the perfect urban infrastructure has positive impact 
on the health of urban inhabitant and the development of education which has important influence on social progress $[25,26]$.

Urban infrastructure environmental benefit is the impact of urban infrastructure on protecting urban natural ecological environment. Some scholars held that the development of green infrastructure is a strategically important process for the creation of ecologically friendly urban environment, as well as for the satisfaction of socioeconomic needs of city dwellers without harming the nature [27]. Other scholars assessed the environmental impacts of sanitation infrastructures such as sewer infrastructure and waste collection system through Life Cycle Assessment [28, 29]. Urban green infrastructure can also mitigate urban warming $[30,31]$ and improve air quality by reducing the concentrations of nitrogen dioxide and particulate matter $[32,33]$.

In summary, the positive impacts of urban infrastructure on economy, society, and environment are obvious. Moreover, different benefits of urban infrastructure can affect each other. Increasing urban infrastructure economic benefit promotes the raise of urban income level and improves urban living condition which is helpful to raise its social benefit. The increase of urban economic and social development levels is beneficial to add the investment on urban infrastructure and improve its technology level which has positive impact on the protection of urban natural environment. The raise of urban infrastructure environmental benefit is conducive to attract investment and beautify residential environment which promotes the improvements of its economic and social benefits. Therefore, urban infrastructure economic, social, and environmental benefits should be emphasized equally and developed in harmony. Urban infrastructure benefit will be raised only if these three benefits are well coordinated.

Nevertheless, the comprehensive evaluation of urban infrastructure benefit was relatively scarce. Some previous researches also referred to the whole benefit of urban infrastructure but they studied one of three benefits of urban infrastructure such as its economic benefit or environmental benefit $[34,35]$. Others evaluated three benefits of one kind of urban infrastructure such as urban public transportation infrastructure and analyzed their coordinated development level [36]. Fewer scholars studied the relationship among three benefits of urban infrastructure. More suitable indexes and more reliable methods are required to achieve a more scientific and comprehensive understanding of urban infrastructure benefit. This paper takes four Chinese autonomous municipalities, which are Beijing, Tianjin, Shanghai, and Chongqing, as examples to analyze the coupling coordination among different benefits of urban infrastructure. They are the more developed regions in China. Their investment and construction scales of urban infrastructure are giant and increasing quickly year by year. But its basic function has not been fully fulfilled in these four cities. Whether these three benefits of urban infrastructure have been developed in harmony or not was unclear. Therefore, this paper tries to study the coordinated development among these three benefits of urban infrastructure in these four cities and analyze the impact of each benefit on their coordinated development. A comprehensive approach of analyzing the coordinated development among three benefits of urban infrastructure was put forward in this study $[35,36]$. The evaluation indicator system would be established according to the relevant theories and previous studies at first. It reflected the content of urban infrastructure benefit more comprehensively and objectively. Then coupling coordination degree model was applied to evaluate the coordinated development level among three benefits of urban infrastructure. It was a useful approach for measuring interactive effect among systems. Then the impact of each benefit on coupling coordination degree among three benefits of urban infrastructure was studied using panel regression model. One important aspect of this approach was the integration of many techniques to analyze urban infrastructure benefit. The capability of analyzing the realistic problems of special regions while making use of available data was its another important feature. It was helpful to realize the interaction among three benefits and the impact of each benefit on it.

The rest of this paper is organized as follows. Section 2 constructs the evaluation indicator system of urban infrastructure benefit and introduces the techniques used in this paper. The results of empirical analysis are revealed in Section 3. Section 4 discusses this result. And Section 5 summarizes the main conclusions and provides the policy implications.

\section{Methodology}

\subsection{Evaluation Indicator System}

2.1.1. Three Benefits of Urban Infrastructure and Their Coordinated Development. The main content of urban infrastructure economic benefit in this paper refers to the impact of urban infrastructure on urban economic system. Many scholars have proved that core infrastructures such as transportation, energy, water, post, and telecommunication have important influence on economic development [37-41]. Urban economic system can be decomposed into four parts which are consumption, investment, government purchase, and external demand according to the national economic identity in macroeconomics theory. The impacts of urban infrastructure on these four parts are named as consumption effect, investment effect, government purchase effect, and external demand effect respectively [34]. These four effects constitute urban infrastructure economic benefit in this paper.

The principal content of social benefit refers to social progress and comprehensive development of human. According to the Human Development Index (HDI) which was presented by the United Nations Development Program (UNDP), the comprehensive development level of human is mainly measured by the levels of income, health, and education. Therefore, urban infrastructure social benefit mainly refers to the impacts of urban infrastructure on the levels of urban inhabitant income, health, and education. Many kinds of urban infrastructures such as transportation, energy, water, and telecommunication have positive influences on 
income growth by increasing employment [21-24]. The use of urban infrastructure is beneficial to urban inhabitant health. Some of them provide the basic condition for improving urban inhabitant health such as health, energy, water, and environmental infrastructures [25, 26, 42, 43]. Transportation infrastructure raises inhabitant health level by reducing the occupancy of traffic accidents and the emission of pollutants $[44,45]$. Telecommunication infrastructure is also helpful to inhabitant health by spreading health information [46]. The well-conditioned urban infrastructure ensures the operation of schools which is beneficial to enroll many students [4749]. It is conducive to raise the level of urban inhabitant education.

Urban infrastructure environmental benefit mainly emerges from the use of urban sanitation and environmental infrastructures. It can be decomposed into three aspects. Firstly, urban sanitation infrastructure has the function of controlling pollution. It collects and disposes urban daily waste intensively which reduces the negative impact of waste on urban natural environment. We can name this aspect as treating waste effect. Secondly, urban public green space and park raise urban green plant coverage ratio. The green plant is helpful to reduce the concentration of pollutants and hazardous substances in the urban air. This aspect can be named as purifying air effect. Thirdly, urban public green space and park can reduce heat island effect and regulate climate through decreasing temperature and humidity. We can name it as regulating climate effect. These three effects constitute urban infrastructure environmental benefit [35].

The utilization level of urban infrastructure is highly related to the relationship among these three benefits. Their coordinated and synchronized development is helpful to raise the whole level of urban infrastructure benefit. Otherwise, the rise of urban infrastructure benefit will be prevented by the uncoordinated development of its three benefits. Specially, three benefits of urban infrastructure are interconnected and interactive. Firstly, urban infrastructure provides the fundamental condition for urban economic growth and is the basis of urban economic development. The level of urban infrastructure economic benefit not only determines the level and quality of urban economic development but also has impact on some indicators of social development such as employment, income, health, education, and so on. When the level of urban infrastructure economic benefit is raised, many industries of economic system can provide more jobs to increase the levels of urban employment and income. The increase of urban economic development is beneficial to add the investment on the fundamental public service which is helpful to improve urban medical condition and living environment and refine the supply of educational resources. It is conducive to raise the levels of urban public health and education which helps to promote the progress of urban society. At the same time, improving urban infrastructure social benefit is also helpful to raise the level of its economic benefit. The construction of urban infrastructure provides many jobs for urban dwellers and raises the level of their income which is beneficial to stimulate urban consumption. The increase of urban consumption means the expansion of urban market demand. It can attract the investors to enlarge the scale of urban investment. In addition, the perfect urban infrastructure improves the levels of urban public health and education. It provides the necessary human capital for urban development and strengthens the potential of urban development which accelerates the development of urban economy. Therefore, urban infrastructure economic benefit and social benefit affect each other interactively.

Secondly, raising the level of urban infrastructure environmental benefit mainly depends on enlarging the scale of urban sanitation and environmental infrastructures and raising their technology level and utilization efficiency. It is highly related to the levels of urban infrastructure economic benefit and social benefit. The improvement of urban infrastructure economic benefit means that the quality of urban economic development is increased. On the one hand, the raise of urban economic development level can increase the input on urban sanitation and environmental infrastructures, especially their technology levels, to increase their utilization levels which is beneficial to protect urban natural environment effectively. On the other hand, increasing the quality of urban economic development is helpful to decrease the consumption of urban natural resources and energy. It helps to reduce the level of urban environmental pollution and raise the level of urban environmental protection. The raise of urban infrastructure social benefit strengthens the potential of urban development to achieve urban sustainable development which has positive impact on the protection of urban environment. Meanwhile, the raise of urban infrastructure social benefit promotes the increase of urban social civilization level and improves urban overall appearance. It is helpful to raise the level of urban environmental protection.

Thirdly, raising the levels of urban infrastructure economic benefit and social benefit is also highly related to the improvement of its environmental benefit. The rise of urban infrastructure environmental benefit not only provides the excellent living condition for urban inhabitants but also creates the perfect circumstance for investors which is helpful to increase the scale of urban investment. The improvement of urban natural environment is beneficial to attract the inflow of external population which helps to increase the demand of urban consumption. It is conducive to raise the level of urban consumption. The level of urban income will be raised correspondingly. In addition, promoting the increase of urban infrastructure environmental benefit can raise the level of urban public health by improving residential environment.

In a word, urban infrastructure economic, social, and environmental benefits are interdependent and interactive. The level of one of three benefits has an obvious impact on the levels of the other two. Therefore, the utilization level of urban infrastructure can be improved only if the developments of these three benefits are coordinated. The development of one of them stops or delays prevents the developments of the other two. It is unfavorable to the increase of the whole benefit of urban infrastructure. Therefore, the coordinated development of urban infrastructure economic, social, and environmental benefits refers to the state of mutual influence, common development among them. The level of their coordinated development is vital to the utilization level of urban 
infrastructure and has an important influence on the whole development of urban infrastructure benefit.

\subsubsection{Construction of Evaluation Indicator System. According} to the content of urban infrastructure economic, social, and environmental benefits, this paper designed an evaluation indicator system which comprised 54 indicators to evaluate urban infrastructure benefits of four cities (Table 1). It was composed of three levels. The first one was the attribute level, second was dimensional level, and third was indicator level. Each indicator reflected the impact of urban infrastructure on urban economic, social, and environmental systems so that it contained two parts which were urban infrastructure and urban economic, social, and environmental systems.

Urban infrastructure included transportation, energy, water, post and telecommunication, health, environmental, and sanitation infrastructures. Transportation infrastructure contained urban internal transportation and external transportation. Urban internal transportation mainly referred to urban bus and rail transit whose scale could be reflected by their traffic operating mileages and operating vehicles. Urban external transportation contained railway, highway, river, seaport, air, and so on. Here we selected railway operating mileage and highway operating mileage as the indicators of urban external transportation because these two transport modes were the major ways of external transportation. Therefore, the traffic operating mileage was the sum of the mileages of urban bus, rail transit, railway, and highway. It reflected the scale and construction level of urban transportation infrastructure. The traffic operating vehicle was the sum of operating vehicles of urban bus and rail transit. These two indicators were selected as the indicators of urban transportation infrastructure. Energy and water infrastructures contained gas supply pipeline, heating supply pipeline, power generation, water supply pipeline, and so on. Considering the realistic situation of four Chinese autonomous municipalities, this paper selected water and gas supply pipeline and total power generation as the indicators of urban energy and water infrastructures. And this paper chose the number of post and telecommunication bureau and the number of telephone subscribers at the end of year as the indicators of post and telecommunication infrastructures. They stood for the scale of built post and telecommunication bureau and the usage amount of telecommunication infrastructure separately. Urban sanitation infrastructure was represented by household waste hazard-free treatment factory, polluted water treatment factory, and special vehicle for urban appearance and sanitation. They were used to remove urban waste and polluted water and sweep urban street respectively. The area of garden green space in built-up area was selected as the indicator of urban environmental infrastructure. And the number of beds in hospitals represented the ability of providing medical services which was the indicator of health infrastructure.

The indicators of four parts of urban economic system would be chosen in the following section. Firstly, household final consumption expenditure was chosen as the indicator of consumption. This indicator reflected the final consumption demand of urban residents. Secondly, the investment level was expressed by gross capital formation. This indicator showed the total amount of capital which could form investment capability. Thirdly, the government purchasing power was the basis of government consumption which finally resulted in the consumption expenditure of government. Thus, government final consumption expenditure was selected as the indicator of government purchase. Finally, this paper chose net export of goods and services as the indicator of external demand. The well-conditioned urban infrastructures could raise the production capacity of the city and facilitate its connection with other regions which was helpful to expand its export.

Next the indicators of three parts of urban social system would be selected. Urban inhabitant income level could be represented by disposable income per capita. It reflected the living standard of urban residents to a certain extent. The rise of health level demonstrated the extension of average life expectancy which meant the decrease of death rate of population. The death rate of population was selected as the indicator of urban inhabitant health level. Raising the level of education was primarily achieved by enrolling more students. Here the number of student enrollments of regular higher education school was regarded as the indicator of urban inhabitant education level. And it showed urban development potential in the future.

Last the indicators of three parts of urban environmental system would be chosen. The level of treating waste was indicated by urban household waste hazard-free treatment rate, urban sewage treatment rate, and urban area under cleaning program. They reflected the ability of treating waste of urban sanitation infrastructure. The effectiveness of purifying air could be shown by the excellent rate of air ambient quality and daily average levels of pollutants such as particulate matter, $\mathrm{NO}_{2}$ and $\mathrm{SO}_{2}$. And regulating climate mainly involved decreasing temperature and humidity. Therefore, its level would be represented by urban average annual temperature and relative humidity. The levels of purifying air and regulating climate were impacted by the change of the area of garden green space in built-up area.

2.1.3. Calculation Method of Each Indicator. As the amount of urban infrastructure changes, its benefit will also undergo changes. The value of each indicator should show its change degree along with the change of urban infrastructure. It will reflect how significantly urban infrastructure impacts each indicator. Consequently, according to the elastic calculation formula in economics, the calculating method of each indicator is shown by the following formula:

$$
\text { Effect }_{i, t}=\frac{\Delta Y_{i} / Y_{i, 0}}{\Delta X / X_{0}}=\frac{\left(Y_{i, t}-Y_{i, 0}\right) / Y_{i, 0}}{\left(X_{t}-X_{0}\right) / X_{0}}
$$

where $Y_{i, 0}$ represents the observed value of the $i$ th indicator of economic, social, or environmental system in initial year and $Y_{i, t}$ represents it in year $t$; $X_{0}$ represents the amount of urban infrastructure in initial year and $X_{t}$ represents it in year $t$; Effect ${ }_{i, t}$ is the impact of urban infrastructure on the $i$ th indicator of economic, social, or environmental system 
TABLE 1: An evaluation indicator system for urban infrastructure benefit.

Level 1

Government purchase effect $\left(U_{13}\right)$

External demand effect $\left(U_{14}\right)$

Income effect $\left(U_{21}\right)$

Social benefit $\left(U_{2}\right)$
Resident health
effect $\left(U_{22}\right)$

Development potential effect $\left(U_{23}\right)$
Consumption effect of traffic operating mileage $\left(U_{111}\right)$

Consumption effect of traffic operating vehicle $\left(U_{112}\right)$ Consumption effect of length of water and gas supply pipeline $\left(U_{113}\right)$

Consumption effect of total power generation $\left(U_{114}\right)$

Consumption effect of the number of post and telecommunication bureau $\left(U_{115}\right)$ Consumption effect of the number of telephone subscribers at the end of year $\left(U_{116}\right)$ Investment effect of traffic operating mileage $\left(U_{121}\right)$ Investment effect of traffic operating vehicle $\left(U_{122}\right)$ Investment effect of length of water and gas supply pipeline $\left(U_{123}\right)$ Investment effect of total power generation $\left(U_{124}\right)$

Investment effect of the number of post and telecommunication bureau $\left(U_{125}\right)$ Investment effect of the number of telephone subscribers at the end of year $\left(U_{126}\right)$

Government purchase effect of traffic operating mileage $\left(U_{131}\right)$

Government purchase effect of traffic operating vehicle $\left(U_{132}\right)$

Government purchase effect of length of water and gas supply pipeline $\left(U_{133}\right)$

Government purchase effect of total power generation $\left(U_{134}\right)$

Government purchase effect of the number of post and telecommunication bureau $\left(U_{135}\right)$ Government purchase effect of the number of telephone subscribers at the end of year $\left(U_{136}\right)$

External demand effect of traffic operating mileage $\left(U_{141}\right)$

External demand effect of traffic operating vehicle $\left(U_{142}\right)$

External demand effect of length of water and gas supply pipeline $\left(U_{143}\right)$

External demand effect of total power generation $\left(U_{144}\right)$

External demand effect of the number of post and telecommunication bureau $\left(U_{145}\right)$

External demand effect of the number of telephone subscribers at the end of year $\left(U_{146}\right)$ Income effect of traffic operating mileage $\left(U_{211}\right)$ Income effect of traffic operating vehicle $\left(U_{212}\right)$ Income effect of length of water and gas supply pipeline $\left(U_{213}\right)$ Income effect of total power generation $\left(U_{214}\right)$

Income effect of area of garden green space in built-up area $\left(U_{215}\right)$ Income effect of the number of telephone subscribers at the end of year $\left(U_{216}\right)$ Income effect of number of beds in hospitals $\left(U_{217}\right)$ Resident health effect of traffic operating mileage $\left(U_{221}\right)$ Resident health effect of traffic operating vehicle $\left(U_{222}\right)$ Resident health effect of length of water and gas supply pipeline $\left(U_{223}\right)$ Resident health effect of total power generation $\left(U_{224}\right)$

Resident health effect of area of garden green space in built-up area $\left(U_{225}\right)$ Resident health effect of the number of telephone subscribers at the end of year $\left(U_{226}\right)$

Resident health effect of number of beds in hospitals $\left(U_{227}\right)$

Development potential effect of traffic operating mileage $\left(U_{231}\right)$

Development potential effect of traffic operating vehicle $\left(U_{232}\right)$

Development potential effect of length of water and gas supply pipeline $\left(U_{233}\right)$

Development potential effect of total power generation $\left(U_{234}\right)$

Development potential effect of area of garden green space in built-up area $\left(U_{235}\right)$ Development potential effect of the number of telephone subscribers at the end of year $\left(U_{236}\right)$ 
TABLE 1: Continued.

\begin{tabular}{|c|c|c|}
\hline Level 1 & Level 2 & Level 3 \\
\hline \multirow{9}{*}{$\begin{array}{l}\text { Environmental } \\
\text { benefit }\left(U_{3}\right)\end{array}$} & \multirow{3}{*}{$\begin{array}{l}\text { Treating waste } \\
\text { effect }\left(U_{31}\right)\end{array}$} & $\begin{array}{l}\text { Level of household waste hazard-free treatment of household waste hazard-free treatment } \\
\text { factory }\left(U_{311}\right)\end{array}$ \\
\hline & & Level of urban sewage treatment of polluted water treatment factory $\left(U_{312}\right)$ \\
\hline & & $\begin{array}{l}\text { Level of road sweeping and cleaning of special vehicle for urban appearance and sanitation } \\
\qquad\left(U_{313}\right)\end{array}$ \\
\hline & \multirow{4}{*}{$\begin{array}{l}\text { Purifying air effect } \\
\qquad\left(U_{32}\right)\end{array}$} & Level of excellent rate of air ambient quality $\left(U_{321}\right)$ \\
\hline & & Level of average daily particulate matter $\left(U_{322}\right)$ \\
\hline & & Level of average daily $\mathrm{NO}_{2}\left(U_{323}\right)$ \\
\hline & & Level of average daily $\mathrm{SO}_{2}\left(U_{324}\right)$ \\
\hline & \multirow{2}{*}{$\begin{array}{l}\text { Regulating climate } \\
\quad \text { effect }\left(U_{33}\right)\end{array}$} & Level of average annual temperature $\left(U_{331}\right)$ \\
\hline & & Level of average annual relative humidity $\left(U_{332}\right)$ \\
\hline
\end{tabular}

in year $t$. It indicates how much the change percentage of each indicator of urban economic, social, and environmental systems is when urban infrastructure changes $1 \%$. In other words, it means the impact of urban infrastructure on each indicator of these three systems.

The required data mainly came from China Statistics Yearbook 2004-2016 and the Yearbook 2004-2016 of every city. Here this paper took the data of year 2003 as the base when calculating the change rate of each variable. This makes the index value of each year be calculated under the same standard. It also can avoid the severe fluctuation of the indicator's value owing to the different base period data.

2.2. The Overall Process of Empirical Analysis. As in previous studies $[35,36]$, the overall process of analyzing the coupling coordination among three benefits of urban infrastructure contains three steps in this paper. Firstly, the indexes of three benefits of urban infrastructure are calculated to evaluate their levels. Secondly, the coupling coordination degree among three benefit is calculated according to the values of three benefits. Thirdly, the influences of three benefits on their coupling coordination degree is investigated.

2.2.1. Calculation of Urban Infrastructure Benefit Index. Before evaluating the level of urban infrastructure benefit, the weights of all of the indicators should be determined. This paper adopts the entropy method to calculate the weight of each indicator. Generally speaking, the entropy which is used in the field of economy and management refers to the information entropy and is the measure of the system's disorder state. It is commonly believed that the value of information entropy which means the variation degree of each indicator is proportional to the equilibrium degree of the system structure. The higher the variation degree is, the greater the weight of the indicator is. Three benefits of urban infrastructure varied in these four cities from 2004 to 2015. The larger the change range of indicator's value was, the larger its impact on the level of urban infrastructure benefit was. The weight of each indicator reflects the impact of its value on the level of urban infrastructure benefit. Therefore, the weight of each indicator is calculated according to its entropy value. The detailed steps are as follows.
Step 1. Standardize the indicators by the standardized method. Different data has different measurement and magnitude. In order to eliminate the influence of dimension and magnitude, the raw data need to be standardized using the following formulas:

$$
\begin{aligned}
Y_{i j} & =\frac{X_{i j}-\min \left\{X_{j}\right\}}{\max \left\{X_{j}\right\}-\min \left\{X_{j}\right\}}, \\
Y_{i j} & =\frac{\max \left\{X_{j}\right\}-X_{i j}}{\max \left\{X_{j}\right\}-\min \left\{X_{j}\right\}} .
\end{aligned}
$$

where $X_{i j}$ is the observed value of the $j$ th indicator in year $i ; \max \left\{X_{i j}\right\}$ is the maximum observed value; $\min \left\{X_{i j}\right\}$ is the minimum observed value; $Y_{i j}$ is the normalized value. When the increasing value of indicator raised the level of urban infrastructure benefit, formula (2) is applied. When the decreasing value of indicator raised the level of urban infrastructure benefit, formula (3) is applied. In this paper, the values of all of the indicators of resident health effect, purifying air effect, and regulating climate effect are calculated by formula (3) except for $U_{321}$. The values of other indicators are calculated by formula (2).

Step 2. Calculate the proportion of the $j$ th indicator value in year $i$ :

$$
\omega_{i j}=\frac{Y_{i j}}{\sum_{i=1}^{m} Y_{i j}},
$$

where $\omega_{i j}$ represents the proportion of the $j$ th indicator value in year $i$.

Step 3. Calculate the information entropy of each indicator and the redundancy degree of the information entropy:

$$
\begin{aligned}
& e_{j}=-\frac{1}{\ln m} \sum_{i=1}^{m}\left(\omega_{i j} \times \ln {\omega_{i j}}\right) . \\
& d_{j}=1-e_{j},
\end{aligned}
$$

where $e_{j}$ is defined as the information entropy of the $j$ th indicator; $0 \leq \mathrm{e}_{\mathrm{j}} \leq 1, d_{\mathrm{j}}$ is the redundancy degree of the information entropy. 
Step 4. Calculate the weight:

$$
w_{j}=\frac{d_{j}}{\sum_{j=1}^{m} d_{j}},
$$

where $w_{j}$ is the weight of the $j$ th indicator.

Step 5. Calculate the urban infrastructure benefit index:

$$
S_{\text {benefit }, i}=\sum_{j=1}^{n} w_{j} Y_{i j}
$$

where $S_{\text {benefit, } i}$ is the urban infrastructure benefit in year $i$.

2.2.2. Coupling Coordination Degree Model. This paper introduces the concept of coupling in physics to calculate the coupling degree of three benefits of urban infrastructure in these four cities [50-53]. Coupling refers to the dynamic relationship which is mutually influenced among different systems. Coupling degree reflects the correlation degree among systems. The more the linkages among systems are, the larger the correlation degree is. There are many interactions among three benefits of urban infrastructure. Their coupling degree could impact the whole level of urban infrastructure benefit. But in some cases it does not tell the synergies among systems. The coordination degree is used to reflect the synergies among systems [51-53]. Therefore, this paper will construct a coupling coordination degree model to analyze the coordinated development degree among three benefits of urban infrastructure. The coupling coordination degree model is given in the following formulas:

$$
\begin{aligned}
H & =\sqrt{C \times S_{\text {benefit }}} . \\
C & =\left[\frac{U_{1} \times U_{2} \times U_{3}}{\left(U_{1}+U_{2}+U_{3}\right)^{3}}\right]^{1 / 3} . \\
U_{l i} & =\sum_{j=1}^{p} w_{j} Y_{i j}
\end{aligned}
$$

where $H$ represents the coupling coordination degree and $H \in(0,1) ; C$ represents the coupling degree among three benefits; $U_{l i}$ represents the level of $l$ th benefit in year $i ; p$ is the number of the indicators at the next lower level of $l$ th benefit. In this paper, $U_{1}, U_{2}$, and $U_{3}$ represent economic benefit, social benefit, and environmental benefit of urban infrastructure, respectively.

The coordinated development levels of different systems were divided into ten classes according to the values of coupling coordination degree [51]. The discriminating standard is shown in Table 2.

2.2.3. Panel Regression Model. The coupling coordination degree among three benefits of urban infrastructure shows the coordinated development level among three benefits. Therefore, generally speaking, the coupling coordination degree is influenced by the levels of these three benefits. Once
TABLE 2: Discriminating standard of the class of coupling coordination development.

\begin{tabular}{lc}
\hline$H$ & class \\
\hline $0.000-0.100$ & Extremely unbalanced development \\
$0.101-0.200$ & Seriously unbalanced development \\
$0.201-0.300$ & Moderately unbalanced development \\
$0.301-0.400$ & Slightly unbalanced development \\
$0.401-0.500$ & Barely unbalanced development \\
$0.501-0.600$ & Barely balanced development \\
$0.601-0.700$ & Slightly balanced development \\
$0.701-0.800$ & Moderately balanced development \\
$0.801-0.900$ & Favorably balanced development \\
$0.901-1.000$ & Superiorly balanced development \\
\hline
\end{tabular}

the level of one benefit changes, the proportional relationship among these three benefits will be altered correspondingly. It will further affect their coordinated development level. In a word, the change of anyone of three benefits will exert an impact on their coupling coordination degree which results in the change of their coordinated development level. So how much are these three benefits impact on their coupling coordination degree is also an issue worthy of in-depth study.

In order to analyze the impacts of three benefits on their coupling coordination degree, panel regression model should be established. The model is shown as follows:

$$
H_{i, t}=\alpha_{0}+\alpha_{1} U_{1 i, t}+\alpha_{2} U_{2 i, t}+\alpha_{3} U_{3 i, t}+\varepsilon_{i, t},
$$

where $H_{i, t}$ is the coupling coordination degree of city $i$ at year $t ; U_{1 i, t}, U_{2 i, t}$, and $U_{3 i, t}$ represent the economic benefit, social benefit, and environmental benefit of urban infrastructure of city $i$ at year $t$ respectively; $\alpha_{0}$ represents constant term and the parameters $\alpha_{1}, \alpha_{2}$, and $\alpha_{3}$ represent the elasticity estimates of $H$ with respect to $U_{1}, U_{2}$, and $U_{3}$ respectively.

\section{Results}

3.1. Changes of Benefit Index Value. We standardized the indicators by formula (1) or (2) at first. Then we calculated the weight of each indicator using the entropy method. The weight of each effect was calculated by adding up the weights of its indicators at the next lower level. Then the weight of each benefit was calculated by adding up the weights of all of its effects. The results were displayed in Tables 3 and 4 . As shown in Table 3, the weight values of these effects have no obvious difference in different cities except for a few of them. The values in Table 4 indicated that the weight of environmental benefit was lowest in all of these four cities. The weight of economic benefit was largest in Beijing and Chongqing and that of social benefit in Tianjin and Shanghai. The highest weight values of three benefits of four cities were between 0.4 and 0.5 except that of Tianjin whose highest weight value was higher than 0.5 . The lowest weight values were smaller than 0.2 except for that of Beijing whose lowest weight value was larger than 0.2 . The results revealed that the differences among the weights of three benefits were large in these four cities. 
TABLE 3: Weights of urban infrastructure benefit indicators of four cities (2004-2015).

\begin{tabular}{|c|c|c|c|c|}
\hline Indicator & Beijing & Tianjin & Shanghai & Chongqing \\
\hline Consumption effect $\left(U_{11}\right)$ & 0.0935 & 0.0778 & 0.0887 & 0.0766 \\
\hline Investment effect $\left(U_{12}\right)$ & 0.0908 & 0.0841 & 0.0909 & 0.0954 \\
\hline Government purchase effect $\left(U_{13}\right)$ & 0.0981 & 0.0850 & 0.0842 & 0.0908 \\
\hline External demand effect $\left(U_{14}\right)$ & 0.1200 & 0.1216 & 0.0764 & 0.1892 \\
\hline Income effect $\left(U_{21}\right)$ & 0.1006 & 0.1456 & 0.1315 & 0.1674 \\
\hline Resident health effect $\left(U_{22}\right)$ & 0.0758 & 0.1711 & 0.1847 & 0.0462 \\
\hline Development potential effect $\left(U_{23}\right)$ & 0.1937 & 0.2043 & 0.1792 & 0.1898 \\
\hline Treating waste effect $\left(U_{31}\right)$ & 0.0531 & 0.0344 & 0.0771 & 0.0389 \\
\hline Purifying air effect $\left(U_{32}\right)$ & 0.1430 & 0.0425 & 0.0300 & 0.0692 \\
\hline Regulating climate effect $\left(U_{33}\right)$ & 0.0315 & 0.0335 & 0.0573 & 0.0365 \\
\hline
\end{tabular}

TABLE 4: Weights of three benefits of urban infrastructure of four cities (2004-2015).

\begin{tabular}{lcccc}
\hline Indicator & Beijing & Tianjin & Shanghai & Chongqing \\
\hline Economic Benefit & 0.4023 & 0.3685 & 0.3402 & 0.4519 \\
Social Benefit & 0.3701 & 0.5211 & 0.4954 & 0.4034 \\
Environmental Benefit & 0.2276 & 0.1104 & 0.1643 & 0.1446 \\
\hline
\end{tabular}

The levels of urban infrastructure benefit of four cities were calculated by formula (7). As illustrated in Figure 1, all of these four cities showed obvious decrease trends of the levels of urban infrastructure benefit except for a few of years. The value of urban infrastructure benefit index of Beijing was lower than 0.5 except for 2005 and that of Tianjin was smaller than 0.4 except for 2004 . Its values were also lower than 0.4 in Shanghai and Chongqing except for 2004. The results indicated that all of these four cities should improve their levels of urban infrastructure benefit in the future.

In addition, Figure 1 revealed the change trends of three benefits of urban infrastructure in four cities from 2004 to 2015. There were several interesting findings that could be found according to the trends shown in Figure 1. Firstly, three benefits of each city have not always appeared in the same change trends. For example, the economic benefit of Beijing appeared in different change trend four times and its environmental benefit two times from 2004 to 2015. Three benefits of other three cities appeared in different change trends in many years. Secondly, three benefits of each city have experienced several severe changes from 2004 to 2015. Beijing underwent severe increases of social and environmental benefits in 2005 and then experienced their serious decreases in 2006 . The economic and social benefits of Tianjin decreased severely in 2005. Shanghai experienced evident change of economic benefit in 2005, 2006, and 2014 and decrease of social benefit in 2005. The environmental benefit of Chongqing appeared in larger change in 2005 and 2007 and its social benefit decreased obviously in 2005. Thirdly, the level of each benefit has significant difference among these four cities. The values of economic and social benefits of Beijing were higher than them of other three cities in most years. And the value of environmental benefit of Tianjin was totally higher than them of other three cities in most years.
3.2. Coupling Coordination Degree among Three Benefits of Four Cities. As revealed in Figure 2, the coupling coordination degrees among three benefits of urban infrastructure displayed different change trends in four cities from 2004 to 2015. But all of their values were lower than 0.5. According to the discriminating standard of the class of coupling coordination development in Table 2, the coordinated developments among three benefits of these four cities were all at the levels of unbalanced development from 2004 to 2015. These results showed that the levels of coordinated development among three benefits were low in these four cities. Four cities all have the problem of uncoordinated development among three benefits of urban infrastructure. It was unfavorable to the increase of urban infrastructure benefit.

3.3. Result of Panel Regression. Table 5 showed the descriptive statistics of the variables in the model. To examine the stability of the variable sequences, we must test whether the variables in the model have unit root at first. Fisher-ADF test, Fisher-PP test, and IPS test are the three main test methods which are widely used $[54,55]$. Therefore, this paper applied them to conduct the panel unit root test. Table 6 showed the results of panel unit root tests by these three methods. The results showed that all of the variables were stationary series at first difference level.

Then the bivariate-cointegrated relationship between each benefit and dependent variable was examined. According to the results shown in Table 7, there was a cointegration relationship between each benefit and coupling coordination degree among three benefits at different confidence levels. In addition, the cointegration relationship between coupling coordination degree among three benefits and all of the explanatory variables was checked by the KAO panel test [55]. The result was revealed in Table 8 which demonstrated the significance of ADF test statistics. Therefore, it was certainly 


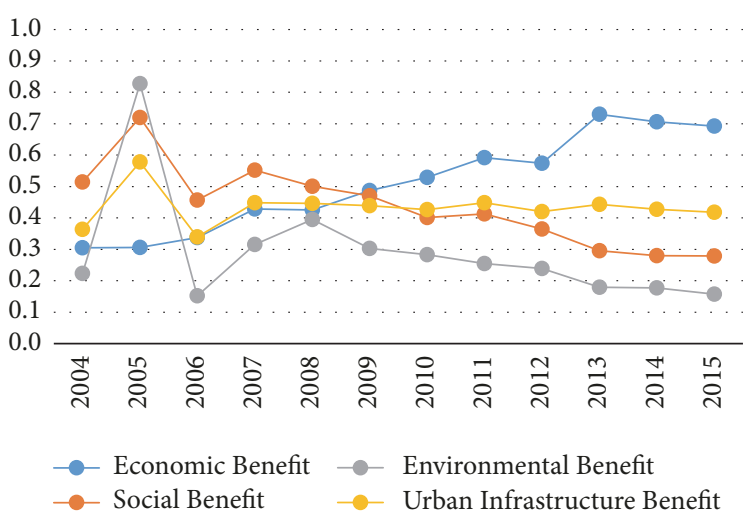

(a) Beijing

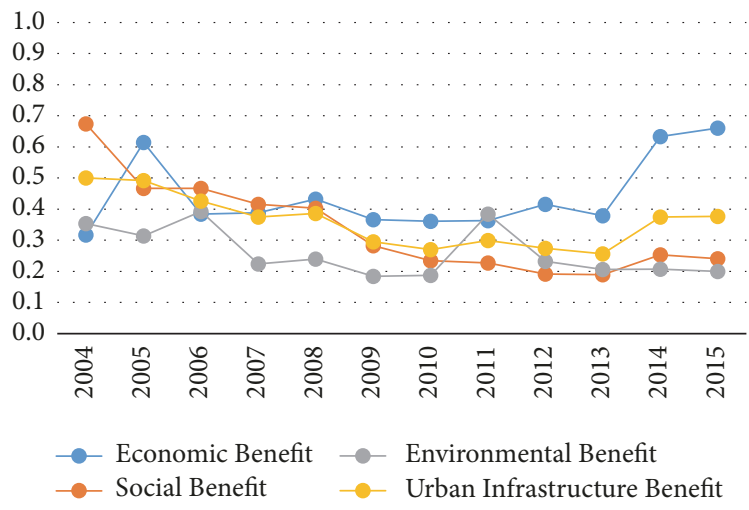

(c) Shanghai

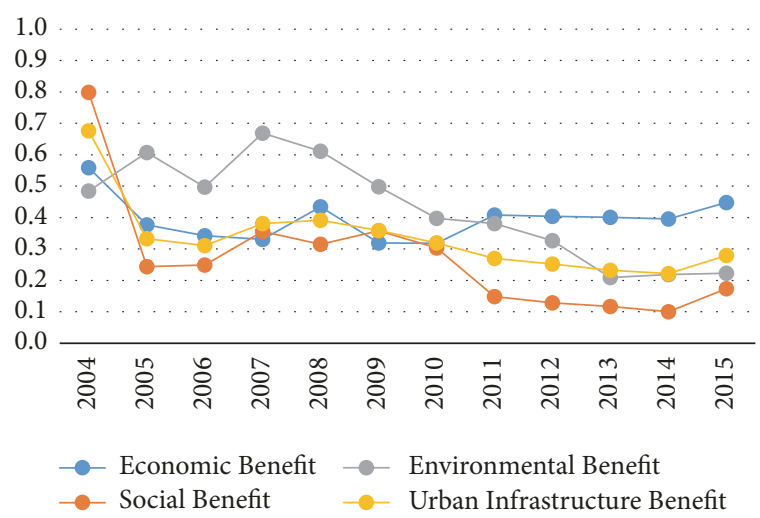

(b) Tianjin

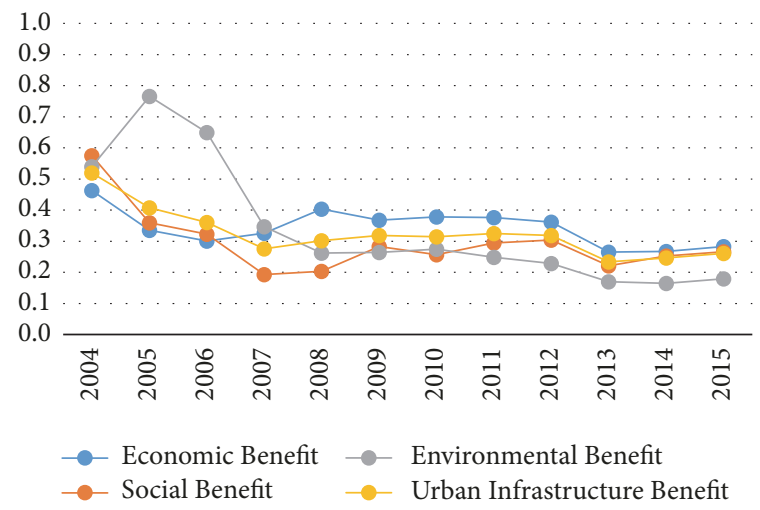

(d) Chongqing

FIGURE 1: Urban infrastructure benefits of four cities.

TABLE 5: The statistical description of the variables used in the analysis.

\begin{tabular}{lccccc}
\hline Variable & $\mathrm{N}$ & Min & Max & Average & Standard variation \\
\hline Coupling coordination degree $(H)$ & 48 & 0.2526 & 0.4693 & 0.3355 & 0.0442 \\
Economic benefit $\left(U_{1}\right)$ & 48 & 0.2654 & 0.7299 & 0.4228 & 0.1209 \\
Social benefit $\left(U_{2}\right)$ & 48 & 0.1000 & 0.7992 & 0.3357 & 0.1546 \\
Environmental benefit $\left(U_{3}\right)$ & 48 & 0.1518 & 0.8278 & 0.3301 & 0.1695 \\
\hline
\end{tabular}

TABLE 6: Results of panel unit root tests.

\begin{tabular}{|c|c|c|c|c|c|c|c|}
\hline & \multirow{2}{*}{ Series } & \multicolumn{2}{|c|}{ Fisher ADF } & \multicolumn{2}{|c|}{ Fisher PP } & \multicolumn{2}{|r|}{ IPS } \\
\hline & & Constant & Trend and Constant & Constant & Trend and Constant & Constant & Trend and Constant \\
\hline \multirow{4}{*}{ Levels } & $H$ & $30.2362^{* * *}$ & $19.0808^{* *}$ & $29.0712^{* * *}$ & $24.6614^{* * *}$ & $-4.2044^{* * *}$ & $-2.0741^{* * *}$ \\
\hline & $U_{1}$ & $17.6232^{* *}$ & $21.3026^{* * *}$ & $17.4442^{* *}$ & $39.7420^{* * *}$ & $-1.8874^{* *}$ & $-2.7089^{* * *}$ \\
\hline & $U_{2}$ & $33.4052^{* * *}$ & $17.2087^{* *}$ & $42.8772^{* * *}$ & $50.6987^{* * *}$ & $-4.5573^{* * *}$ & $-1.9947^{* *}$ \\
\hline & $U_{3}$ & $22.9888^{* * *}$ & $34.5616^{* * *}$ & 12.3602 & $34.5286^{* * *}$ & $-2.7217^{* * *}$ & $-6.7449^{* * *}$ \\
\hline \multirow{4}{*}{ First difference } & $H$ & $36.6378^{* * *}$ & $25.8390^{* * *}$ & $47.2893^{* * *}$ & $48.8948^{* * *}$ & $-5.7703^{* * *}$ & $-2.3682^{* * *}$ \\
\hline & $U_{1}$ & $40.0063^{* * *}$ & $33.4023^{* * *}$ & $55.6334^{* * *}$ & $62.5841^{* * *}$ & $-5.8070^{* * *}$ & $-4.3860^{* * *}$ \\
\hline & $U_{2}$ & $32.4436^{* * *}$ & $22.3941^{* * *}$ & $59.2405^{* * *}$ & $48.7459^{* * *}$ & $-4.3216^{* * *}$ & $-2.1093^{* *}$ \\
\hline & $U_{3}$ & $51.7019^{* * *}$ & $41.8429^{* * *}$ & $64.4322^{* * *}$ & $52.4095^{* * *}$ & $-10.8196^{* * *}$ & $-7.0836^{* * *}$ \\
\hline
\end{tabular}

Note: Lags are all selected automatically by AIC and SC standard.

${ }^{*}$ Means significant at confidence level $10 \%$.

** Means significant at confidence level 5\%.

${ }^{* * *}$ Means significant at confidence level $1 \%$. 
TABLE 7: Testing for bivariate-cointegration between coupling coordination degree and each effect.

\begin{tabular}{|c|c|c|c|}
\hline Test statistics & Economic benefit $\left(U_{1}\right)$ & Social benefit $\left(U_{2}\right)$ & Environmental benefit $\left(U_{3}\right)$ \\
\hline Panel v-Statistic & -0.2340 & -0.3739 & 1.0294 \\
\hline Panel rho-Statistic & $-3.7702^{* * *}$ & $-2.1613^{* *}$ & $-1.4915^{*}$ \\
\hline Panel PP-Statistic & $-14.4577^{* * *}$ & $-4.4487^{* * *}$ & $-4.1896^{* * *}$ \\
\hline Panel ADF-Statistic & $-3.6428^{* * *}$ & $-2.9157^{* * *}$ & -1.2241 \\
\hline Group rho-Statistic & $-1.3989^{*}$ & 0.5700 & -0.5653 \\
\hline Group PP-Statistic & $-9.8327^{* * *}$ & $-4.2708^{* * *}$ & $-4.4439^{* * *}$ \\
\hline Group ADF-Statistic & $-3.0833^{* * *}$ & $-2.7978^{* * *}$ & -0.9734 \\
\hline
\end{tabular}

Note: Lags are all selected automatically by AIC and SC standard.

${ }^{*}$ Means significant at confidence level $10 \%$.

** Means significant at confidence level $5 \%$.

${ }^{* * *}$ Means significant at confidence level $1 \%$.

TABLE 8: Kao panel cointegration test.

\begin{tabular}{lcccc}
\hline $\begin{array}{l}\text { Panel of four } \\
\text { cities }\end{array}$ & $\begin{array}{l}\text { ADF test } \\
\text { statistics }\end{array}$ & $\begin{array}{l}\text { Residual } \\
\text { variance }\end{array}$ & $\begin{array}{c}\text { HAC } \\
\text { variance }\end{array}$ & $\begin{array}{c}\text { Probability } \\
\text { value }\end{array}$ \\
\hline & -3.0100 & 0.2173 & 0.0422 & 0.0013 \\
\hline
\end{tabular}

Note: $\mathrm{H}_{0}$, there is no cointegration relationship between the variables. $\mathrm{H}_{1}$, there is a cointegration relationship between the variables.

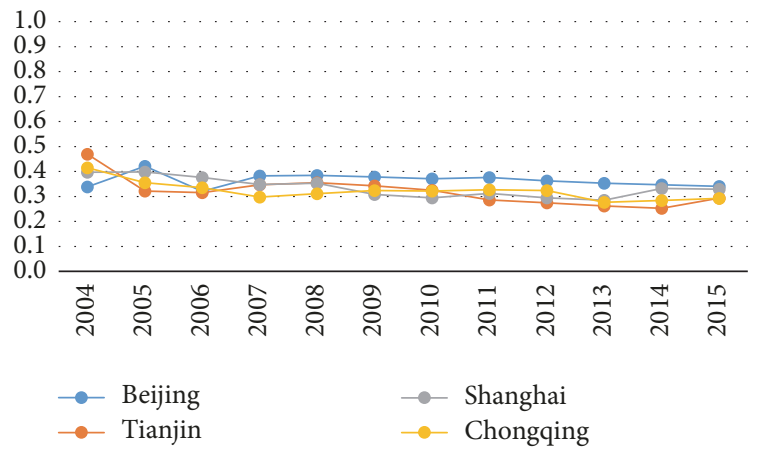

FIgURE 2: Coupling coordination degree of three benefits of urban infrastructure in four cities.

believed that the cointegration relationship between variables existed at the significance level of 1 percent.

Next the type of panel model will be chosen. The panel model usually contains three types which are mixed effects model, fixed effects model, and random effects model. The methods of selecting the type of panel model include the likelihood ratio test and the Hausman test. The likelihood ratio test is used to select between mixed effects model and fixed effects model. If the P-value of the F-test statistic is smaller than the given significance level, the fixed effects model will be chosen. Otherwise, the mixed effects model will be selected. The Hausman test is used to choose between fixed effects model and random effects model. If the P-value of its statistic is less than the hypothetical significance level, we will build the fixed effects model; if not, the random effects model will be applied. We employ the likelihood ratio test to choose between mixed effects model and fixed effects model at first. If the mixed effects model is rejected, the Hausman test will be used to select between fixed effects model and random effects model. For this case, the results of the Hausman test
TABLE 9: Panel data model selection.

\begin{tabular}{lc}
\hline Test type & \\
\hline Likelihood ratio test & $2.4863^{* *}$ \\
Hausman test & 4.3833 \\
Model Type & RE \\
\hline
\end{tabular}

Note: FE is fixed effects model. ${ }^{* * *}$ Means significant at confidence level $1 \%$.

TABLE 10: Panel regression model estimation results.

\begin{tabular}{lc}
\hline Variables & \\
\hline Economic benefit $\left(U_{1}\right)$ & $0.3177^{* * *}$ \\
Social benefit $\left(U_{2}\right)$ & $0.8804^{* * *}$ \\
Environmental benefit $\left(U_{3}\right)$ & $0.3753^{* * *}$ \\
Constant & 0.0843 \\
$\mathrm{R}^{2}$ & 0.9282 \\
Adjusted $\mathrm{R}^{2}$ & 0.9228 \\
F-statistic & $172.3358^{* * *}$ \\
Sum squared residuals & 2.9446 \\
S. E. of regression & 0.2713 \\
D. W. & 2.4151 \\
Obs. & 144 \\
Individuals & 4 \\
\hline
\end{tabular}

Note: ${ }^{* * *}$ Means significant at confidence level $1 \%$.

and the likelihood ratio test suggested that random effects model should be used to analyze the impacts of three benefits on coupling coordination degree among them in four cities (Table 9).

The estimation results were shown in Table 10, which showed that the impacts of three benefits were statistically significant. The result of F-test indicated the significance of the model. All of the regression coefficients were positive meant that three benefits were all positively related to their 
coupling coordination degree. The elasticity of social benefit was greatest $(0.8804)$, indicating that a $1 \%$ increase in the level of social benefit would lead to $0.8804 \%$ increase in coupling coordination degree among three benefits when other factors kept constant. The elasticity of economic benefit was smallest (0.3177). The results revealed that social benefit was the main contributor to increase coupling coordination degree among three benefits of four cities and environmental benefit is the second and economic benefit is the least. Promoting the progress and development of urban society is the fundamental function of urban infrastructure. The difference among the elasticity of three benefits was obvious. It showed that the impacts of three benefits on coupling coordination degree among them were different.

\section{Discussion}

This paper analyzed the relationship among three benefits of urban infrastructure in four Chinese autonomous municipalities and compared them. Moreover, the impacts of three benefits on their coupling coordination degree were studied in this paper. The research results showed that the coordinated development of three benefits of urban infrastructure has some problems in these four cities and the impacts of three benefits on it were different.

Generally speaking, this paper has two main findings. The first finding was that the levels of coordinated development among three benefits of urban infrastructure were low in these four cities. The result indicated that the impacts of urban infrastructure on economy, society and environment were obviously different. Three benefits of urban infrastructure often appeared bigger distinction. It also coincided with the fact that the change trends of three benefits were different in these four cities. In recent years, the contradiction among economic, social and environmental systems was highlighted in these four cities. Although the investment of urban infrastructure was continually rising, the function of urban infrastructure has not been shown sufficiently. Some kinds of urban infrastructure were excessive while others were not enough. The structure of urban infrastructure did not satisfy the demand of urban development. The ability of urban infrastructure to promote the coordinated development of economy, society, and environment needs to be increased continually in the future.

The second one was that the impact of social benefit was largest on coupling coordination degree among these three benefits. As important public goods, urban infrastructure is a basic condition to the development of urban society. It provides the fundamental guarantee for human development. Human development is regarded as the main manifestation of social progress. Raising the level of human development is helpful to strengthen the capability of human which is the fundamental demand of economic development. At the same time, the raise of economic and social development level is beneficial to reduce the consumption of resources which is helpful to protect natural environment. The results of this paper proved that the raise of urban infrastructure social benefit was helpful to promote the improvement of other two benefits which resulted in the more coordinated development of these three benefits in these four cities. It generally confirms the universal knowledge that one of the basic functions of urban infrastructure is promoting social progress.

\section{Conclusion and Policy Implications}

In conclusion, the results suggested that the levels of coordinated development among three benefits of urban infrastructure were low in these four cities and the impact of its social benefit on their coordinated development was largest. Therefore, urban infrastructure social benefit needs to be improved mainly in these four cities.

This paper proposes the following policy implications. First, four cities should strengthen the function of urban infrastructure in the process of social development. The development of urban infrastructure should satisfy the need of urban social development. The rapid development of urban infrastructure leads to the increase of labor demand. It is beneficial to raise the levels of employment and average wage which further promotes the raise of urban living quality and social progress. Four cities should highly pay attention to this point. In the future, the related agencies of urban infrastructure should add their jobs and enhance their wage levels. Moreover, urban infrastructure should adopt advanced technology to reduce its emission of pollutants. Urban environmental infrastructure should raise its capability of absorbing contaminant in the air. It is helpful to purify urban ecological environment which results in the improvement of residential health situation. The well-conditioned urban infrastructure provides excellent service and circumstances for the daily operation of high school. It is beneficial to enroll more students into high school which raises the education levels of these four cities.

Second, economic and environmental benefits of urban infrastructure also should be valued highly. Developing urban economy and protecting natural environment are also the main goals of building urban infrastructure. Four cities should highly emphasize the correlation between urban infrastructure and economic system and mainly raise the productive efficiency of transportation, energy, water, and telecommunication infrastructures. Their market-oriented operations should be insisted from now on. In addition, four cities should enlarge the scale of urban environmental infrastructure and increase its input. For example, four cities could establish the minimum standard of urban green area to ensure the supply of urban green infrastructure. The related agencies of urban environmental infrastructure should carry out strict supervision and management.

Last, four cities should attach importance to the proportion among different benefits of urban infrastructure. Economic, social, and environmental benefits of urban infrastructure organically constituted the whole urban infrastructure benefit. Their development levels should close in general. And their performances must be controlled and regulated strictly. In addition, the structure of urban infrastructure should fit the demand of urban development. Four cities 
should amplify the construction of urban infrastructure which is short. In these ways, the gap among different benefits of urban infrastructure can be narrowed.

This approach can be further improved by incorporating more suitable indicators and using more advanced techniques. The indicators of urban infrastructure can be extended to intangible infrastructures such as education, social security, and so on. These infrastructures provide the fundamental service and also have obvious benefits. The levels of urban economic, social, and environmental systems can be represented by other appropriate indicators. With the integration of disciplines, more advanced techniques can be introduced to the research of urban infrastructure. The comprehensive analysis of urban infrastructure benefit will be further discussed and deepened. In addition, this approach can be adjusted to fit the context of rural, provincial, national, and international infrastructural benefit.

\section{Conflicts of Interest}

The authors declare that there are no conflicts of interest regarding the publication of this paper.

\section{Acknowledgments}

The research on utilizing efficiency of urban public infrastructure was supported by the National Natural Science Fund Project in 2012, Project approval no. 71273186. Thanks are due to for the editorial efforts made by Xiangchun Li.

\section{References}

[1] A. Pereira and J. Andraz, "On the economic effects of public infrastructure investment: A survey of the international evidence," Journal of Economic Development, vol. 38, no. 4, pp. 1-37, 2013.

[2] B. D. Lewis, "Urbanization and economic growth in indonesia: good news, bad news and (possible) local government mitigation," Regional Studies, vol. 48, no. 1, pp. 192-207, 2014.

[3] Z. Elburz, P. Nijkamp, and E. Pels, "Public infrastructure and regional growth: Lessons from meta-analysis," Journal of Transport Geography, vol. 58, pp. 1-8, 2017.

[4] I. Yakubu, M. A. Akaateba, and B. A. A. Akanbang, "A study of housing conditions and characteristics in the Tamale Metropolitan Area, Ghana," Habitat International, vol. 44, pp. 394-402, 2014.

[5] L. A. Sierra, E. Pellicer, and V. Yepes, "Method for estimating the social sustainability of infrastructure projects," Environmental Impact Assessment Review, vol. 65, pp. 41-53, 2017.

[6] A. Schäffler and M. Swilling, "Valuing green infrastructure in an urban environment under pressure - The Johannesburg case," Ecological Economics, vol. 86, pp. 246-257, 2013.

[7] E. Andersson, S. Barthel, S. Borgström et al., "Reconnecting cities to the biosphere: Stewardship of green infrastructure and urban ecosystem services," AMBIO, vol. 43, no. 4, pp. 445-453, 2014.

[8] W. Y. Chen, "The role of urban green infrastructure in offsetting carbon emissions in 35 major Chinese cities: a nationwide estimate," Cities, vol. 44, pp. 112-120, 2015.
[9] A. H. Munnell, "Policy watch: infrastructure investment and economic growth," The Journal of Economic Perspectives, vol. 6, no. 4, pp. 189-198, 1992.

[10] J. J. Laird, J. Nellthorp, and P. J. Mackie, "Network effects and total economic impact in transport appraisal," Transport Policy, vol. 12, no. 6, pp. 537-544, 2005.

[11] R. P. Pradhan and T. P. Bagchi, "Effect of transportation infrastructure on economic growth in India: The VECM approach," Research in Transportation Economics, vol. 38, no. 1, pp. 139-148, 2013.

[12] Y. J. Zhang and Y. B. Da, “The decomposition of energy-related carbon emission and its decoupling with economic growth in China," Renewable \& Sustainable Energy Reviews, vol. 41, pp. 1255-1266, 2015.

[13] M. Farhadi, "Transport infrastructure and long-run economic growth in OECD countries," Transportation Research Part A: Policy and Practice, vol. 74, pp. 73-90, 2015.

[14] P. N. K. De Silva, S. J. R. Simons, and P. Stevens, "Economic impact analysis of natural gas development and the policy implications," Energy Policy, vol. 88, pp. 639-651, 2016.

[15] I. S. Cruz and T. Katz-Gerro, "Urban public transport companies and strategies to promote sustainable consumption practices," Journal of Cleaner Production, vol. 123, pp. 28-33, 2016.

[16] S. Zailani, M. Iranmanesh, T. A. Masron, and T.-H. Chan, "Is the intention to use public transport for different travel purposes determined by different factors?" Transportation Research Part D: Transport and Environment, vol. 49, pp. 18-24, 2016.

[17] J. Donaubauer, B. Meyer, and P. Nunnenkamp, "Aid, infrastructure, and fdi: assessing the transmission channel with a new index of infrastructure," World Development, vol. 78, pp. 230245, 2016.

[18] P. R. D. Bom and J. E. Ligthart, "What have we learned from three decades of research on the productivity of public capital?" Journal of Economic Surveys, vol. 28, no. 5, pp. 889-916, 2014.

[19] N. Bose and M. E. Haque, "Causality between public investment in transport and communication and economic growth," Journal of Economic Development, vol. 30, no. 1, pp. 95-106, 2005.

[20] A. K. Cosar and B. Demir, "Domestic road infrastructure and international trade: Evidence from Turkey," Journal of Development Economics, vol. 118, pp. 232-244, 2016.

[21] P. Thakuriah Vonu, J. Persky, S. Soot, and P. S. Sriraj, "Costs and benefits of employment transportation for low-wage workers: An assessment of job access public transportation services," Evaluation and Program Planning, vol. 37, pp. 31-42, 2013.

[22] G. Koolwal and D. Van De Walle, "Access to water, women's work, and child outcomes," Economic Development and Cultural Change, vol. 61, no. 2, pp. 369-405, 2013.

[23] M. Wei, S. Patadia, and D. M. Kammen, "Putting renewables and energy efficiency to work: How many jobs can the clean energy industry generate in the US?" Energy Policy, vol. 38, no. 2, pp. 919-931, 2010.

[24] M. M. Albiman and Z. Sulong, "The linear and non-linear impacts of ICT on economic growth, of disaggregate income groups within SSA region," Telecommunications Policy, vol. 41, no. 7-8, pp. 555-572, 2017.

[25] P. Parikh, K. Fu, H. Parikh, A. McRobie, and G. George, "Infrastructure provision, gender, and poverty in indian slums," World Development, vol. 66, pp. 468-486, 2015.

[26] L. Lenz, A. Munyehirwe, J. Peters, and M. Sievert, "Does largescale infrastructure investment alleviate poverty? impacts of 
rwanda's electricity access roll-out program," World Development, vol. 89, pp. 88-110, 2017.

[27] J. Grizāns, A. Auzinš, and J. Vanags, "Green infrastructure development-challenge of the modern urban dynamic growth," Economics and Business, vol. 22, pp. 51-58, 2012.

[28] A. Petit-Boix, D. Sanjuan-Delmás, C. M. Gasol et al., "Environmental assessment of sewer construction in small to medium sized cities using life cycle assessment," Water Resources Management, vol. 28, no. 4, pp. 979-997, 2014.

[29] A. Aranda Usón, G. Ferreira, D. Zambrana Vásquez, I. Zabalza Bribián, and E. Llera Sastresa, "Environmental-benefit analysis of two urban waste collection systems," Science of the Total Environment, vol. 463-464, pp. 72-77, 2013.

[30] T. Matthews, A. Y. Lo, and J. A. Byrne, "Reconceptualizing green infrastructure for climate change adaptation: Barriers to adoption and drivers for uptake by spatial planners," Landscape and Urban Planning, vol. 138, pp. 155-163, 2015.

[31] R. Emmanuel and A. Loconsole, "Green infrastructure as an adaptation approach to tackling urban overheating in the Glasgow Clyde Valley Region, UK," Landscape and Urban Planning, vol. 138, pp. 71-86, 2015.

[32] T. A. M. Pugh, A. R. MacKenzie, J. D. Whyatt, and C. N. Hewitt, "Effectiveness of green infrastructure for improvement of air quality in urban street canyons," Environmental Science \& Technology, vol. 46, no. 14, pp. 7692-7699, 2012.

[33] F. Manes, F. Marando, G. Capotorti et al., "Regulating ecosystem services of forests in ten italian metropolitan cities: air quality improvement by $\mathrm{PM}_{10}$ and $\mathrm{O}_{3}$ removal," Ecological Indicators, vol. 67, pp. 425-440, 2016.

[34] Y. Sun and Y. Cui, "Analyzing urban infrastructure economic benefit using an integrated approach," Cities, vol. 79, pp. 124133, 2018.

[35] Y. Sun, Y. Cui, and H. Huang, "An empirical analysis of the coupling coordination among decomposed effects of urban infrastructure environment benefit: case study of four chinese autonomous municipalities," Mathematical Problems in Engineering, vol. 2016, pp. 1-11, 2016.

[36] Y. Sun and Y. Cui, "Evaluating the coordinated development of economic, social and environmental benefits of urban public transportation infrastructure: Case study of four Chinese autonomous municipalities," Transport Policy, vol. 66, pp. 116126, 2018.

[37] A. P. Elhance and T. R. Lakshmanan, "Infrastructureproduction system dynamics in national and regional systems. An econometric study of the Indian economy," Regional Science \& Urban Economics, vol. 18, no. 4, pp. 511-531, 1988.

[38] D. A. Aschauer, "Is public expenditure productive?" Journal of Monetary Economics, vol. 23, no. 2, pp. 177-200, 1989.

[39] S. Sahoo and K. K. Sexena, "Infrastructure and economic development: some empirical evidence," Indian Economic Journal, vol. 47, no. 2, pp. 54-66, 1999.

[40] C. F. Del Bo and M. Florio, "Infrastructure and growth in a spatial framework: evidence from the EU regions," European Planning Studies, vol. 20, no. 8, pp. 1393-1414, 2012.

[41] J. Donaubauer, B. E. Meyer, and P. Nunnenkamp, "A new global index of infrastructure: construction, rankings and applications," World Economy, vol. 39, no. 2, pp. 87-139, 2016.

[42] J. R. Wolch, J. Byrne, and J. P. Newell, "Urban green space, public health, and environmental justice: The challenge of making cities 'just green enough,' Landscape and Urban Planning, vol. 125, pp. 234-244, 2014.
[43] D. Bennett, "Does clean water make you dirty? Water supply and sanitation in the Philippines," The Journal of Human Resources, vol. 47, no. 1, pp. 146-173, 2012.

[44] P. A. Singleton and K. J. Clifton, "Considering health in US metropolitan long-range transportation plans: A review of guidance statements and performance measures," Transport Policy, vol. 57, pp. 79-89, 2017.

[45] L. A. Meehan and G. P. Whitfield, "Integrating health and transportation in Nashville, Tennessee, USA: From policy to projects," Journal of Transport \& Health, vol. 4, pp. 325-333, 2017.

[46] M. L. Smith, R. Spence, and A. T. Rashid, "Mobile phones and expanding human capabilities," Information Technologies and International Development, vol. 7, pp. 77-88, 2011.

[47] J. Zhang and L. C. Xu, "The long-run effects of treated water on education: The rural drinking water program in China," Journal of Development Economics, vol. 122, pp. 1-15, 2016.

[48] S. Kenyon, "Transport and social exclusion: access to higher education in the UK policy context," Journal of Transport Geography, vol. 19, no. 4, pp. 763-771, 2011.

[49] A. Siddiquah and Z. Salim, "The ICT facilities, skills, usage, and the problems faced by the students of higher education," EURASIA Journal of Mathematics, Science and Technology Education, vol. 13, no. 8, pp. 4987-4994, 2017.

[50] Y. Li, Y. Li, Y. Zhou, Y. Shi, and X. Zhu, "Investigation of a coupling model of coordination between urbanization and the environment," Journal of Environmental Management, vol. 98, no. 1, pp. 127-133, 2012.

[51] Z. Tang, "An integrated approach to evaluating the coupling coordination between tourism and the environment," Tourism Management, vol. 46, pp. 11-19, 2015.

[52] T. Li, Y. Han, Y. Li, Z. Lu, and P. Zhao, "Urgency, development stage and coordination degree analysis to support differentiation management of water pollution emission control and economic development in the eastern coastal area of China," Ecological Indicators, vol. 71, pp. 406-415, 2016.

[53] R. Wang, J. Cheng, Y. Zhu, and P. Lu, "Evaluation on the coupling coordination of resources and environment carrying capacity in Chinese mining economic zones," Resources Policy, vol. 53, pp. 20-25, 2017.

[54] Y. Wang, L. L. Chen, and J. Kubota, “The relationship between urbanization, energy use and carbon emissions: evidence from a panel of Association of Southeast Asian Nations (ASEAN) countries," Journal of Cleaner Production, vol. 112, pp. 1368-1374, 2016.

[55] B. Xu and B. Lin, "Differences in regional emissions in China's transport sector: determinants and reduction strategies," Energy, vol. 95, pp. 459-470, 2016. 


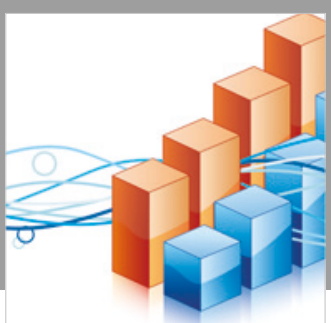

Advances in

Operations Research

\section{-n-m}
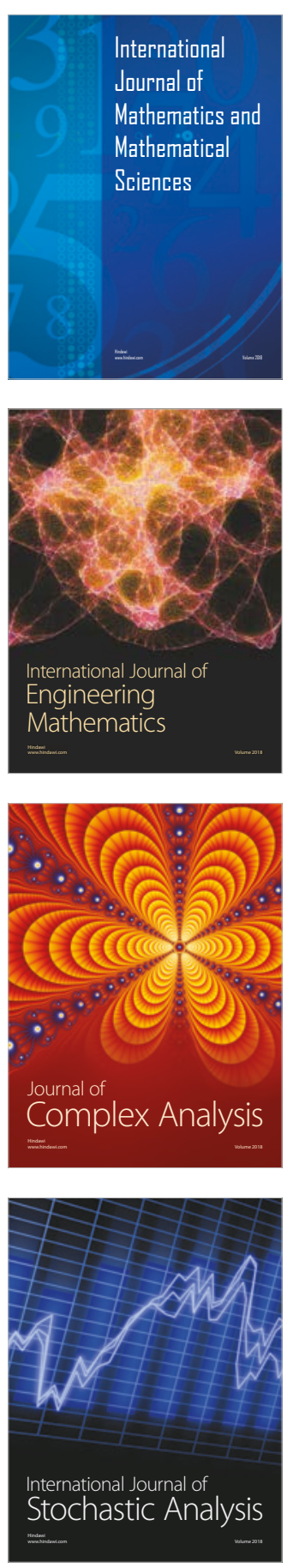
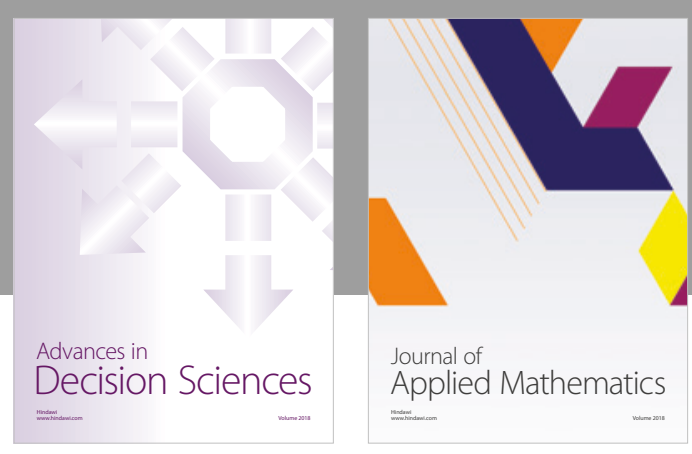

Journal of

Applied Mathematics
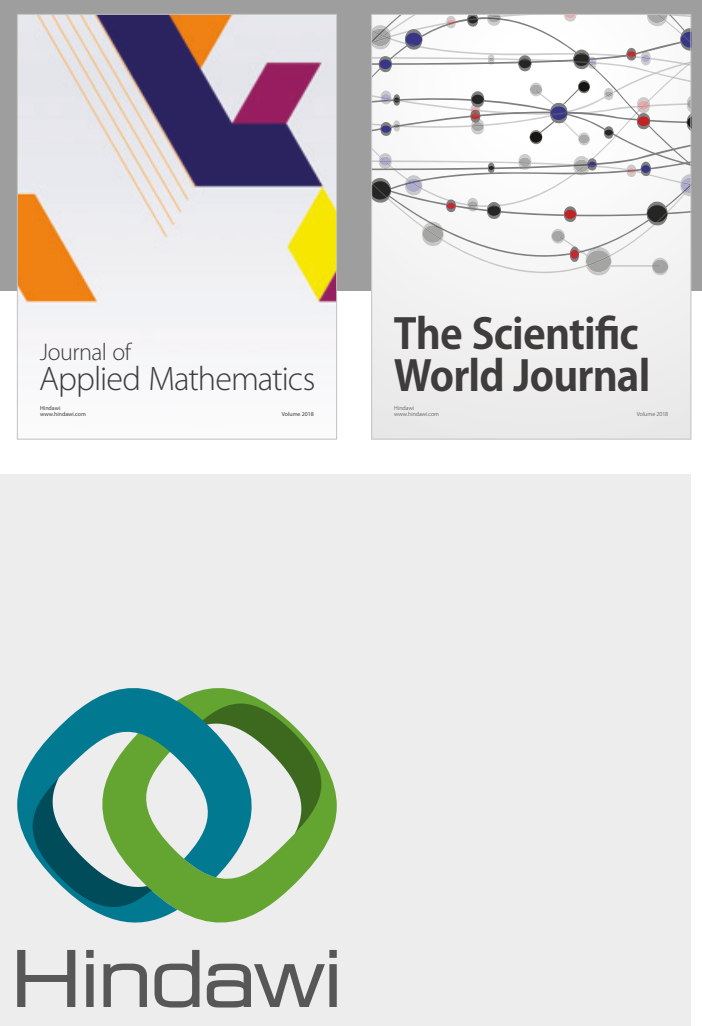

Submit your manuscripts at

www.hindawi.com

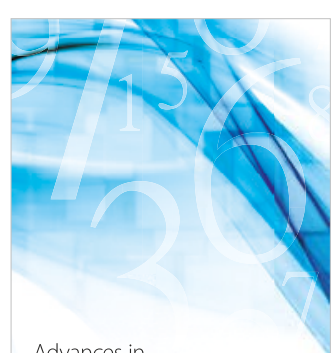

Advances in
Numerical Analysis
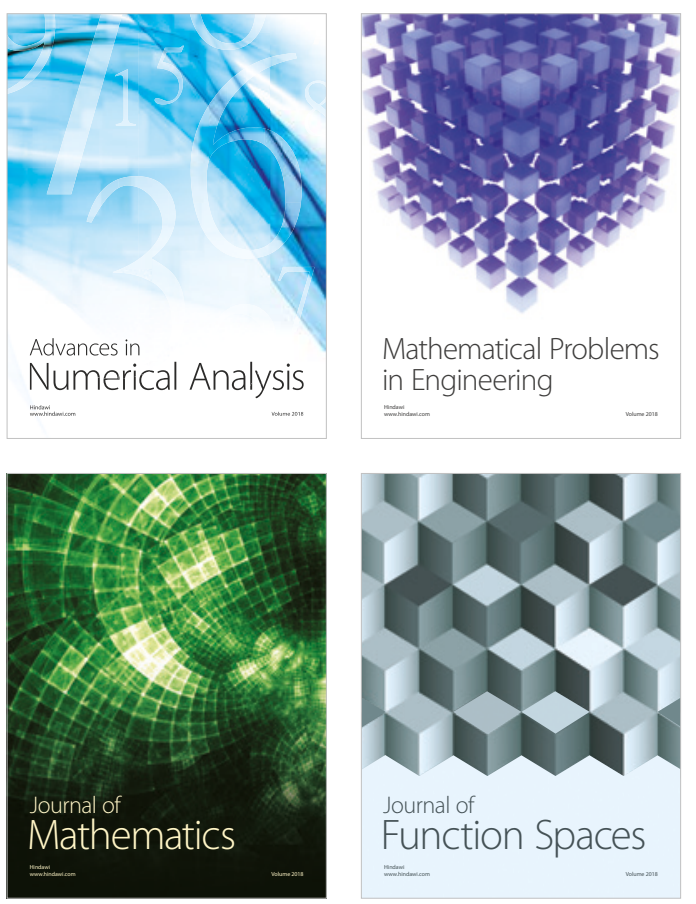

Mathematical Problems in Engineering

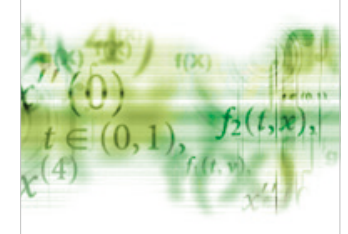

International Journal of

Differential Equations

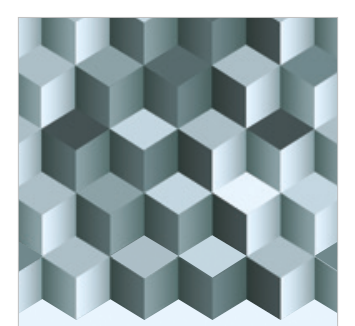

Journal of

Function Spaces

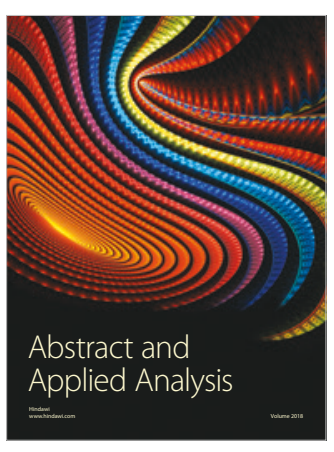

The Scientific

World Journal

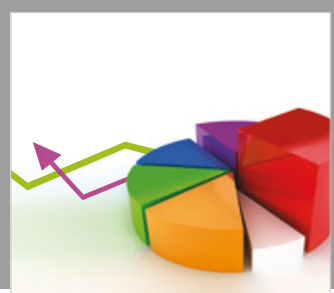

Journal of

Probability and Statistics
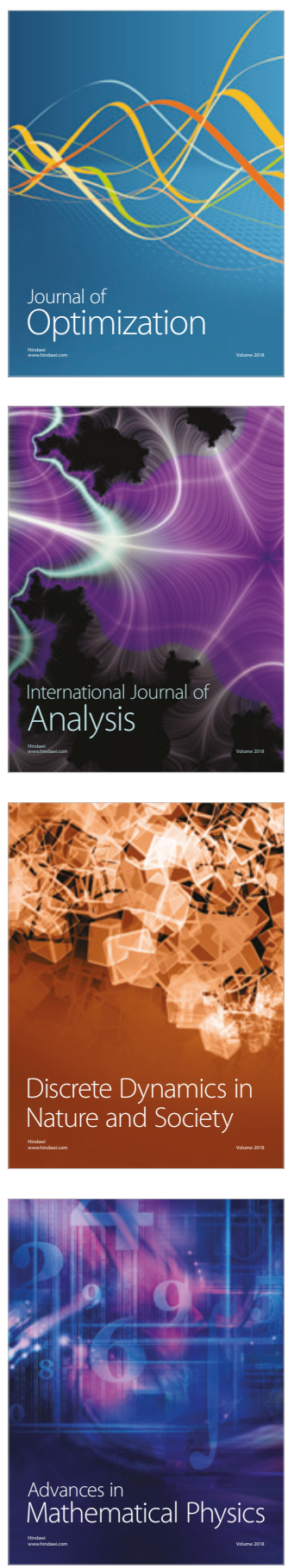